\title{
Development of the posterior lateral line system in Thunnus thynnus, the atlantic blue-fin tuna, and in its close relative Sarda sarda
}

\author{
ALAIN GHYSEN ${ }^{*}, 1, \#$, KEVIN SCHUSTER ${ }^{1, \#, ~ D E N I S ~ C O V E S ~}{ }^{2}$, FERNANDO DE LA GANDARA ${ }^{3}$, \\ NIKOS PAPANDROULAKIS ${ }^{4}$ and AURELIO ORTEGA ${ }^{3}$ \\ ${ }^{1}$ Laboratory of Neurogenetics, INSERM and Université Montpellier, Montpellier, France, \\ 2IFREMER, Laboratoire Aquacole du Languedoc Roussillon, Palavas, France, \\ 3 Instituto Español de Oceanografia (IEO), Centro Oceanografico de Murcia, Puerto de Mazarron, Spain and \\ ${ }^{4}$ Institute of Aquaculture, Hellenic Center for Marine Research, Heraklion, Greece
}

\begin{abstract}
The lateral line system of amphibians and fish comprises a large number of individual mechanosensory organs, the neuromasts, and their sensory neurons. The pattern of neuromasts varies markedly between species, yet the embryonic pattern is highly conserved from the relatively basal zebrafish, Danio rerio, to more derived species. Here we examine in more detail the development of the posterior lateral line (PLL) in embryos and early larvae of one of the most derived fish species, the blue-fin tuna Thunnus thynnus, and of its close relative, the Atlantic bonito Sarda sarda. We show that the basic features of embryonic PLL development, including the migratory properties of the PLL primordium, the patterning of neuromasts and their innervation, are largely conserved between zebrafish and tuna. However, Thunnus and Sarda embryos differ from Danio in three respects: the larger size of the neuromast cupula, the capability of mature neuromasts to migrate dorsally, and the presence of a single, precisely located terminal neuromast.
\end{abstract}

KEY WORDS: neuromast, hair cell, planar polarity, cupula, migrating primordium

The lateral line sensory system is central to many aspects of fish behavior (Coombs and Montgomery, 1999). It comprises a set of discrete sensory organs, the neuromasts. At the core of each neuromast lies a group of mechanosensory hair cells that provide information about local water flow. The system is thought to mediate a sense of "touch-at-a-distance" (Dijkgraaf, 1963) whereby fish can "feel" their surroundings within a radius close to their own body length.

The neuromasts on the body and tail form the posterior lateral line system (PLL). The embryonic PLL is formed by a primordium which migrates from head to tail and deposits small groups of cells, each one a prospective neuromast, in its wake (Metcalfe et al., 1985). In zebrafish, the embryonic PLL comprises 5 neuromasts regularly spaced along the body, and 2-3 terminal neuromasts (Gompel et al., 2001). This pattern is highly conserved in several species of the more derived acanthopterygian group (Pichon and Ghysen, 2004), although adult patterns vary widely across teleo- sts (Webb, 1989). The developmental mechanisms underlying the formation of the zebrafish PLL have been extensively studied over the past 10 years (Ghysen and Dambly-Chaudière, 2007). It is not known if and to what extent the same mechanisms operate in other teleosts.

Here we report our observations on the embryonic and early larval development of the PLL in the Atlantic blue-fin tuna, Thunnus thynnus, an acanthopterygian that shows highly derived features, e.g., endothermy (rev. in Stevens and Neill, 1978) or cooperative hunting (Partridge al., 2004). Some observations were also done on Thunnus' close relative, the bonito (Sarda sarda). Our aim was double: first, to determine to what extent the observed conservation of pattern reflects a conservation of developmental mechanisms, and second, to provide background infor-

Abbreviations used in this paper: PLL, posterior lateral line.

\footnotetext{
*Address correspondence to: Alain Ghysen. cc103, Université Montpellier 2, Place E. Bataillon, 34095 Montpellier, France. e-mail: alain.ghysen@univ-montp2.fr

\#Note: These authors performed the experimental work; the other authors provided the experimental material used in this report.
} 

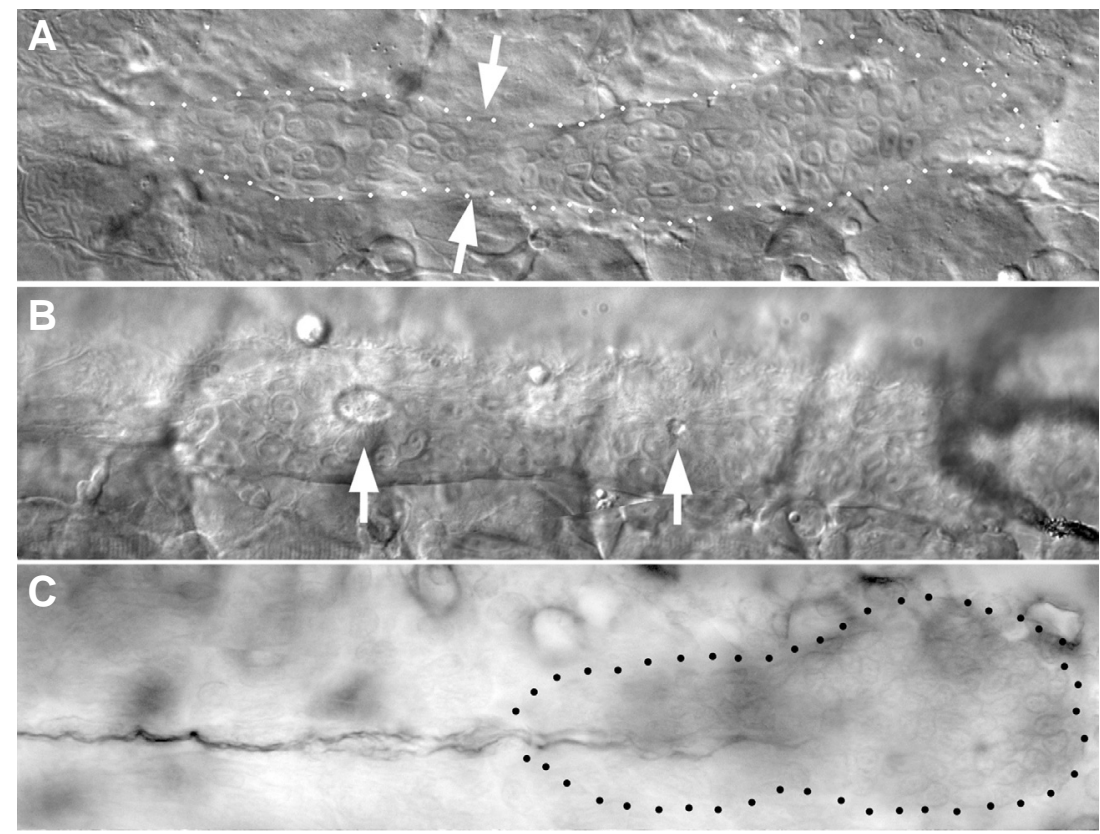

Fig. 1. Migrating posterior lateral line (PLL) primordium in pre-hatch Thunnus embryos. (A) Primordium in the process of depositing a neuromast; arrows indicate the thinning between the migrating cells of the primordium, and the cells that are slowing down. The primordium is migrating to the right. (B) Cavitation of two rosettes (arrows) during primordium migration. (C) Towing of sensory axons revealed by anti-acetylated tubulin immunolabeling. The outline of the primordium is dotted. In all figures, dorsal is up, anterior to the left.

mation about sensory development in blue fin tuna, possibly leading to improvements in the handling of larvae of a threatened species.

\section{Results}

\section{Posterior lateral line primordium and nerve}

We observed a primordium migrating posteriorwards along the horizontal myoseptum in pre-hatch, 28-34hpf (hours postfertilization) Thunnus thynnus embryos (Fig. 1A and Supp. Movie 1). The size and shape of the primordium, and the process of neuromast deposition, resemble very much those documented in zebrafish (Fig. 1A). The organization of the primordium is also very similar in the two species, with 2-3 rosettes in the trailing region prefiguring the next neuromasts to be deposited (Fig. 1B).

It has been proposed in amphibians (Harrison, 1904), and confirmed in zebrafish (Metcalfe, 1985), that growth cones of sensory neurons accompany the primordium, and are guided by its migration (Gilmour, 2004). We labeled Thunnus axons with anti-acetylated tubulin and observed a close association

Fig. 2. Neuromast hair cells. (A-C) Vital fluorescent labeling of hair cells in Thunnus neuromasts. (D-F) Apical surface of hair cells in neuromasts that comprise respectively 18-20,30-32 and close to 50 hair cells. D and $E$ are neuromasts $L 2$ and $L 1$ of the same Thunnus larva, $F$ shows a neuromast in Sarda. (G-H) Antero-posterior polarity of hair cells visualized with fluorescein-coupled phalloidin in neuromasts $L 2, L 3$ and $L 4$ respectively, of the same Thunnus embryo. Arrows: see text. between PLL axons and migrating primordium (Fig. 1C), suggesting that guidance of sensory axons by the primordium also takes place in Thunnus.

\section{Neuromast differentiation}

A few hours after neuromasts have been deposited, cells at their center begin to take up the hair cell specific dye, DiAsp (Fig. 2A). The number of hair cells increases rapidly (Fig. 2B). The neuromasts appear very fragile, however, and labeling often reveals a punctate pattern suggestive of hair cell death (Fig. 2C).

Cilia protruding through the pore of the neuromast can be detected under Nomarski optics (Fig. 2D-F). At late stages of neuromast differentiation, the number of hair cells increases to several tens (Fig. 2F). Labeling the stereocilia with fluorescent phalloidin demonstrates that hair cells are polarized along the antero-posterior axis (Fig. $2 \mathrm{G}-\mathrm{I})$. Young hair cells tend to appear as pairs of unpolarized cells (Fig. 2I, arrows), suggesting that, as in zebrafish, interaction between the two daughters of a hair cell precursor cell leads to their polarization towards each other, thereby generating pairs of cells with opposite polarity (LopezSchier and Hudspeth, 2006).

The cilia of hair cells are embedded in a gelatinous cupula, which can occasionally be seen under Nomarski optics (Fig. 3A-C). Cupulae are much longer in tuna than in zebrafish (as already reported by Kawamura et al., 2003), and reach in excess of $130 \mu \mathrm{m}$, as opposed to an average length of $20-40 \mu \mathrm{m}$ for zebrafish neuromasts (van Trump and McHenry, 2008).
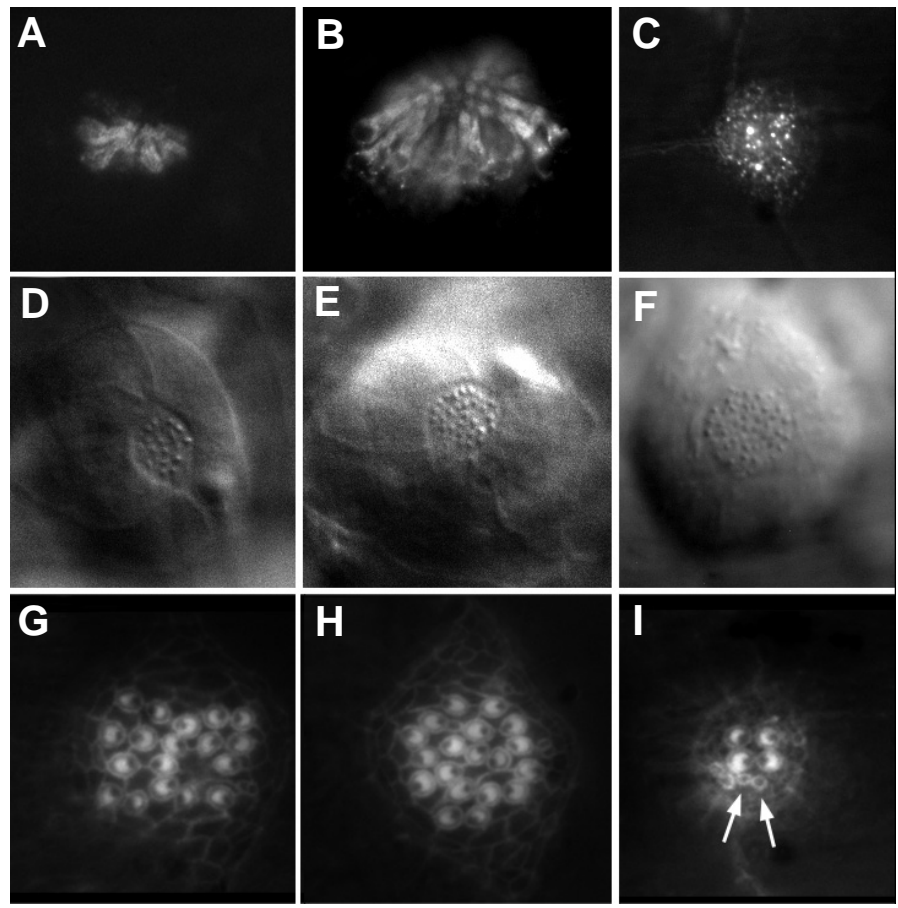
Strands of cells extend between neuromasts (Fig. 3B-E, arrowheads), similar to the stripe of interneuromast cells observed in zebrafish (Grant et al., Lopez-Schier and Hudspeth, 2005). Due to the dorsal migration of L1 (see below), this stripe is best observed between L1 and L2 (Fig. 3F, arrowheads). It seems plausible that this line of cells is at the origin of at least some of the many additional neuromasts observed on adult animals.

Hair cell cilia extend into the surrounding water through a pore in the skin (Fig. 3G, arrow) formed by 3-4 specialized peridermal cells (Fig. 3G, asterisks). In zebrafish, the migration of mature neuromasts involves a translocation of these specialized peridermal cells among their neighbors (Sapède et al., 2002).

\section{Pattern of the embryonic PLL}

Thunnus thynnus embryos have about 40 somites, vs. 32 somites for zebrafish. Their embryonic PLL, as visualized by DiAsp labeling (Fig. 4A) comprises five neuromasts (L1-L5) followed by a terminal one near the tip of the body. Sarda sarda embryos have about 55 somites; their PLL has 6-7 neuromasts, and a terminal one (Supp. Fig. 1A,B). Neuromasts and neuromast innervation can also be visualized by anti-acetylated tubulin immunolabeling (Fig. 4B).

The first PLL neuromast occupies a dorsal position (Fig. 4A,B, Supp Fig. 1). We wondered whether this neuromast might actually correspond to D1, a dorsal neuromast deposited by a later dorsal primordium in zebrafish (Sapède et al., 2001). We settled this question by examining pre-hatch embryos. We found cases where $L 1$ was positioned along the myoseptum (Supp. Fig. 2A). Those were just beginning to differentiate, as evidenced by the presence of only two hair cells. In other cases, L1 was found at more dorsal positions (Supp. Fig. 2B,C), and had an increased number of hair cells. We conclude that L1 is deposited along the horizontal myoseptum, consistent with the observation that the nerve branch to L1 exits from the PLL nerve (Fig. 4B), and migrates soon after deposition to reach a dorsal position after one day (Fig. 4A-C). The migration of $\mathrm{L} 1$ is followed later by a less extensive dorsal migration of L2, and then by L3. Intriguingly, L2 first migrates ventrally as it does in zebrafish, and subsequently migrates dorsally (Supp. Fig. 2 D,E).

The early migration of $L 1$, and resulting extension of its nerve branch, occasionally reveals a splitting of this branch in two tracts (Supp. Fig. 2 F,G). Splitting of the L1 branch, as well as of part of the PLL nerve, was also observed at a later stage, in one out of five cases where we labeled the PLL nerve by an application of the lipophilic dye, Dil, rostral to L1 (Supp. Fig. $2 \mathrm{H}$ ).

The position of PLL neuromasts on the two sides of the body rarely coincides (Supp. Fig. 1B), indicating that the deposition is probably not triggered by spatial landmarks. The distribution of neuromast positions in both Thunnus and Sarda embryos (Fig. 4E,F) shows an increasing dispersion of positions from anterior to posterior neuromasts, as also reported in zebrafish
(Gompel et al., 2001), consistent with the idea that neuromast deposition results from a cyclic process that is intrinsic to the primordium.

\section{Early larval development of the terminal system}

A single terminal neuromast, ter 1 , is found about halfway between the tip of the tail and the posteriormost pigment cell, at the end of Thunnus(Fig. 4A,B) and Sardaembryogenesis (Supp. Fig. 1). The position of ter 1 is precisely determined in both species, as the neuromasts on the two sides of the body always overlap by more than $50 \%$ (see e.g. Fig. 5B-E). A second neuromast, ter2, appears in a more anterior position early during larval life, at 5-6 days post-hatch (dph). ter2 is invariably located close to the posterior edge of a pigment cell which itself occupies a reproducible location on the ventral side of the tail (Fig. $5 \mathrm{C}, 5 \mathrm{~mm}$ larva).

A third neuromast, ter3, forms just posterior to ter2 when the larva reaches $6 \mathrm{~mm}$ (7dph, Fig. 5D). The initial position of ter3 next to ter2 (Fig. 5D), and the fact that its nerve branch always arises from ter2 (Fig. 5F), suggests that ter3 is formed by budding from
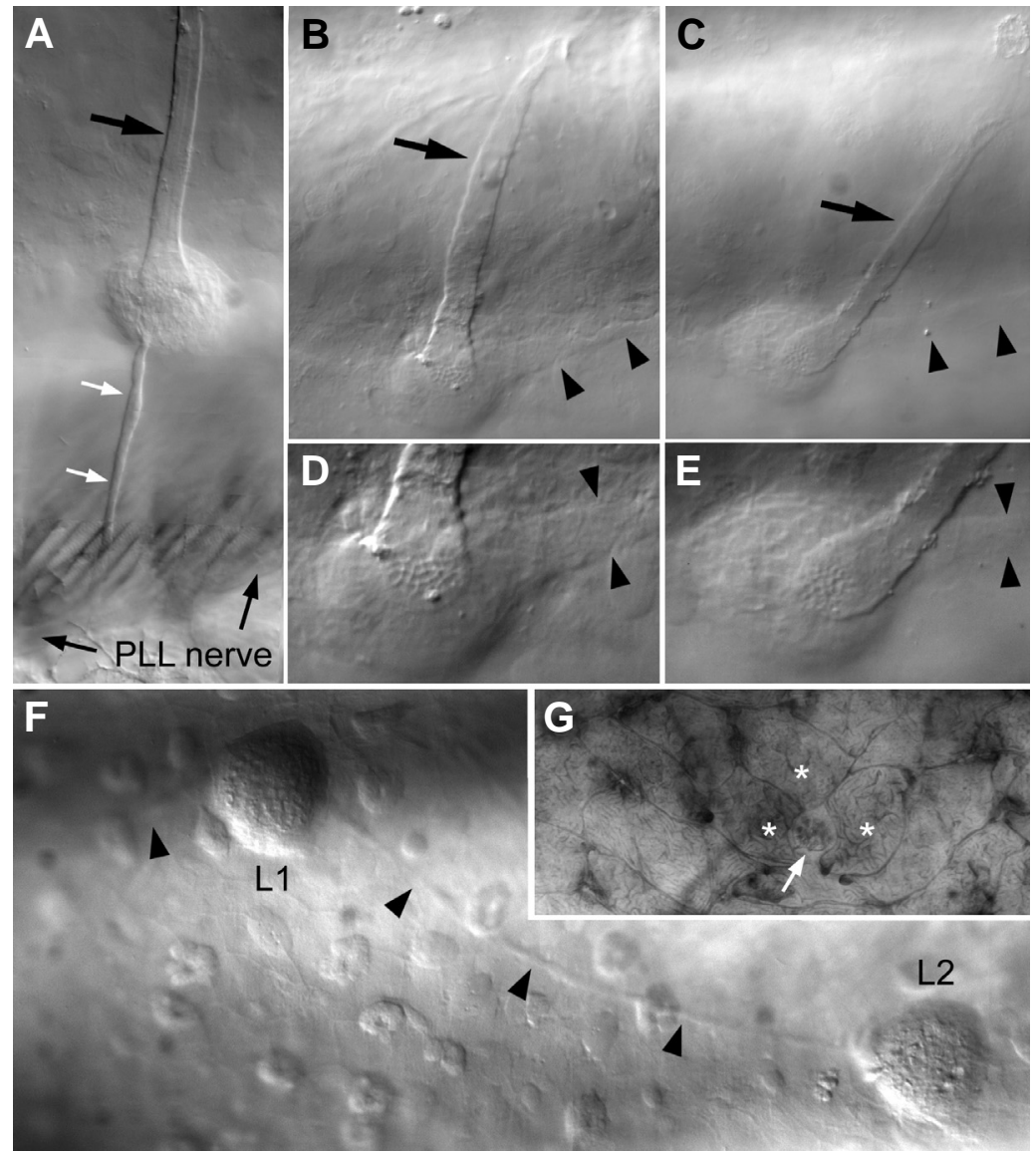

Fig. 3. Embryonic posterior lateral line (PLL) of Sarda embryos. (A-C) neuromasts L1, L2 and L3 of the same embryo. Large arrows indicate the cupula, arrowheads indicate the strand of interneuromast cells, and white arrows indicate the branch of the PLL nerve extending to neuromast $L 1$. (D,E) Higher magnification of panels $B$ and $C$ respectively, showing the tightly packed apical surfaces of hair cells at the base of the cupula. (F) Continuous strand of interneuromast cells extending between L1 and L2. (G) Three peridermal cells (asterisks) form the pore (arrow) through which hair bundles extend into the surrounding water. 

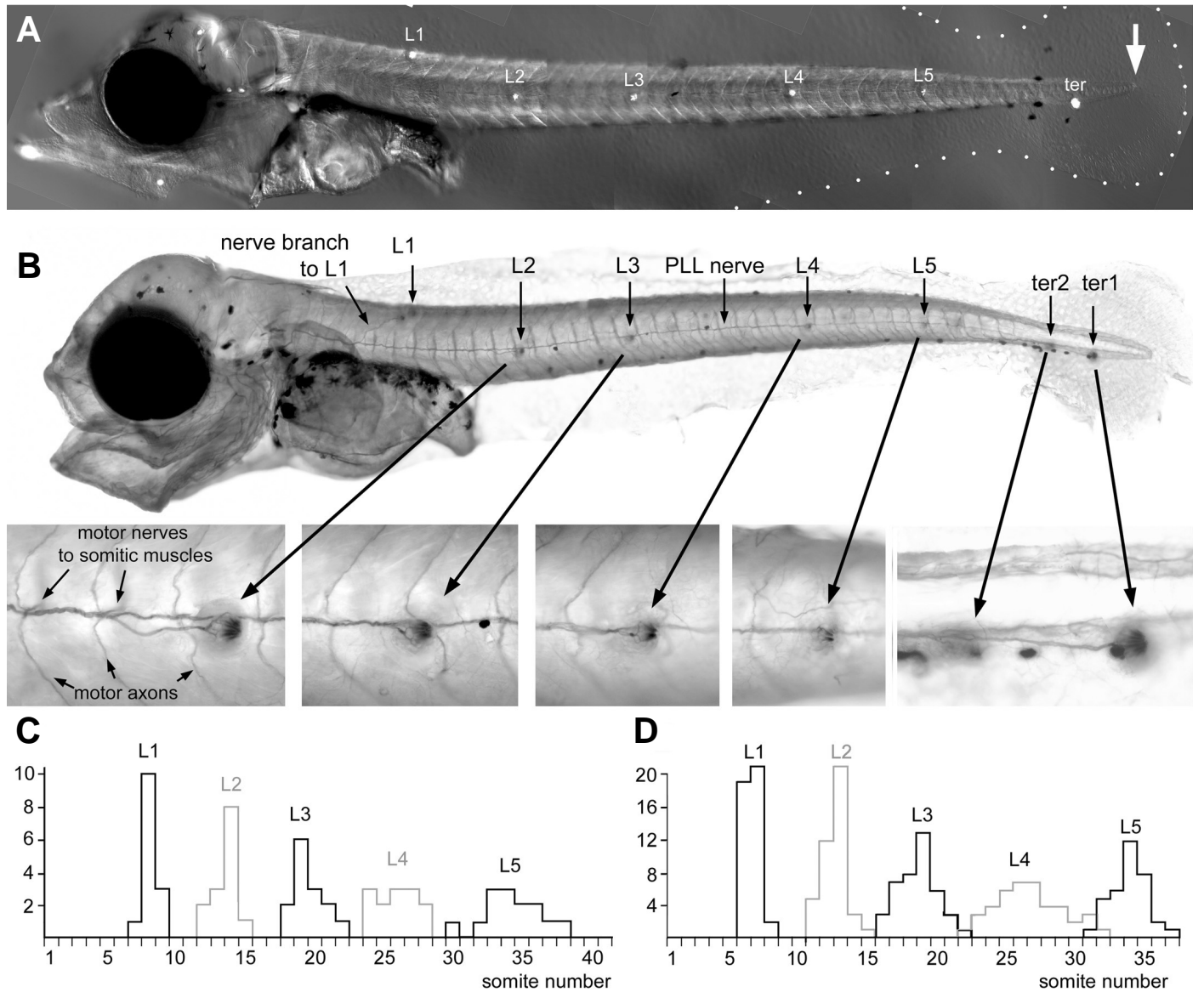

Fig. 4. Posterior lateral line (PLL) pattern. (A) As visualized by DiAsp fluorescent labeling in a 3dph larva. The white arrow marks the tip of the tail. (B) As visualized by anti-acetylated tubulin immunolabeling, in a $3.9 \mathrm{~mm}$ Thunnus larva: notice that the post-embryonic neuromast ter2 is beginning to differentiate. The number of hair cells is $>6$ in L2, 6 in L3, 4 in L4 and 2 in L5. (C,D) Positions of the first five neuromasts in Sarda and Thunnus early larvae, respectively.

ter2 (Wada et al., 2010). ter3 migrates ventro-posteriorly (Fig. $5 E, F)$ above the first hypural plate, $\mathrm{H} 1$, which corresponds to the ventral part of the forming caudal fin (Supp. Fig. 4A). Ter3 eventually buds off a fourth neuromast, ter 4, when the larva reaches $8 \mathrm{~mm}$ ( $9 \mathrm{dph}$, Fig. 5F). There is no further development of the system up to two weeks (10mm larvae, Supp. Figs. 3 and 4B). At this stage, as expected from their position relative to the hypural plates, ter 3 and ter4 are located in the ventral half of the well developed caudal fin, whereas ter1 is located in the dorsal half (Supp. Fig. 4B).

\section{Discussion}

The embryonic PLL of Thunnusis strikingly similar to that of the relatively basal Danio rerio, confirming the conservation of embryonic PLL patterns among teleosts (Pichon and Ghysen, 2004). Here we show that not only the embryonic pattern, but essential aspects of its development, are also conserved: the migrating primordium is accompanied by sensory axons, presents 2-3 rosettes in its trailing region, and deposits neuromasts within which hair cells appear as pairs of opposite polarities, as well as interneuromast cells. These similarities suggest that the major features of PLL development, including the molecular bases of primordium organization and migration, and of neuromast differentiation and innervation, have been conserved throughout teleosts.

We will discuss separately three differences between Thunnus and Danio: the large size of the cupulae, the dorsal migration of $\mathrm{L} 1$, and the early larval development of the terminal system.

The cupulae of tuna embryos reach in excess of $130 \mu \mathrm{m}$, as opposed to an average length of $20-40 \mu \mathrm{m}$ for zebrafish neuromasts. Extrapolating results on the dynamic properties of zebrafish cupulae (van Trump and McHenry, 2008), tuna cupulae should be ten times more sensitive, and have a much lower frequency cut-off value, possibly as low or lower than $1 \mathrm{~Hz}$. This suggests that tuna cupulae are exceedingly sensitive, but unable to provide a frequency analysis of the stimulus. The PLL system would thus mostly be used as trigger for a strike reaction during early larval life: a highly sensitive water movement detector may allow the hatched larva to feed quickly, an essential requirement given that the yolk is completely used one day post-hatch (as opposed to 3-4 days in zebrafish larvae). The size of their cupulae may make tuna neuromasts highly susceptible to shearing forces, which obviously do not exist in their normal environment. The fragility of large cupulae could contribute to the extreme sensitivity of tuna larvae to handling, and may also explain why most 
neuromasts show badly damaged hair cells just after transfer to the DiAsp solution (Fig. 2C), as this transfer necessitates pipetting of the larvae.

Zebrafish neuromasts migrate ventrally, starting with L2, whereas in tuna they migrate dorsally, except for L2 which first migrates ventrally and subsequently veers dorsally. The intriguing behavior of $L 2$ suggests that dorsal migration of PLL neuromasts in tuna has been superimposed on an ancestral tendency to migrate ventrally. The dorsal migration of neuromasts is not specific for perciforms, as dorsally migrated neuromasts have also been reported in medaka (Oryzias latipes, Sapède et al.,
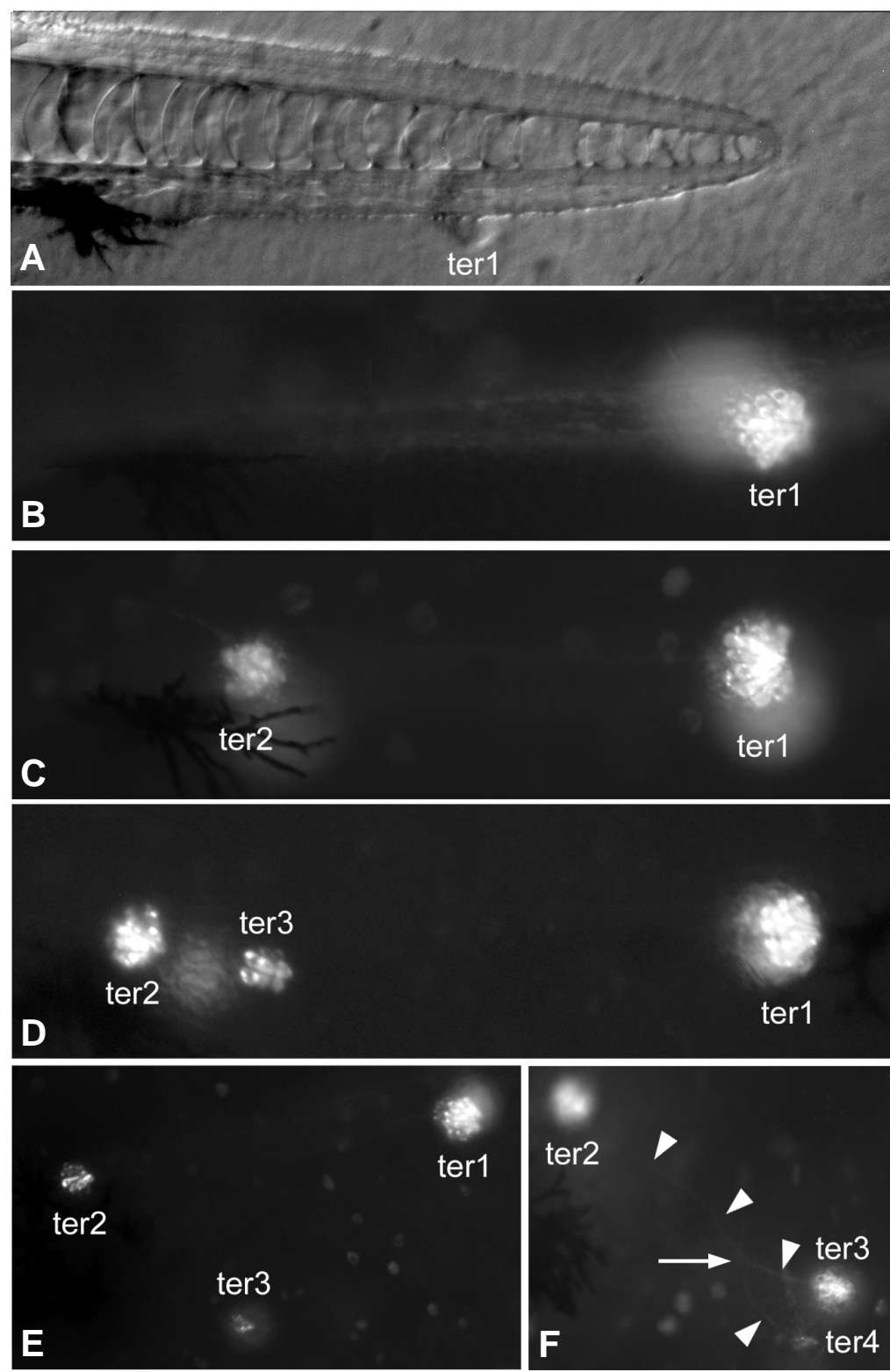

Fig. 5. Development of the terminal pattern. (A) Position of ter1 in a Sarda embryo. (B) At 3dph, only ter1 is present. (C) At $5 d p h$, ter 2 is forming just posterior to a pigment cell. (D) At 7dph, in a $5.9 \mathrm{~mm}$ larva, ter3 is appearing next to ter2. (E) At $8 \mathrm{dph}$, in a $7.6 \mathrm{~mm}$ larva, ter3 is migrating away from ter2. (F) At 9dph, in a $8.1 \mathrm{~mm}$ larva, ter4 has budded off from ter3. arrowheads: afferent fibers; arrow: place where ter 4 split off from ter3, as evidenced by the branching of the afferent fibers (Wada et al., 2010).
2001), which occupies an intermediate level between the basa ostariophysians and the derived perciforms. More species need obviously to be sampled before we can evaluate whether dorsal migration is a monophyletic feature, and at what stage in teleost evolution it is likely to have appeared.

Terminal neuromasts are distinct from the other PLL neuromasts in several respects: not only do they mark the posterior end of the PLL, but in addition they are the starting point of the caudal lines that will later extend along the caudal fin (Wada et al., 2006), and they are deposited ventrally rather than laterally, as the primordium veers ventrally and migrates along the ventral midline shortly before terminal deposition (Gompel et al., 2001). In zebrafish the number of terminal neuromasts is variable (2-3, more rarely 4), as is their position (Wada etal., 2008). Terminal neuromasts undergo a massive rearrangement associated with the dorsal flexure of the notochord, and end up as a vertical row of three neuromasts, T1 to T3 from dorsal to ventral, located on the three caudalmost scales (Wada et al., 2008). T1 and T3 are at the origin of all caudal fin lines in several teleost species, whereas T2, whose position corresponds to the middle of the caudal fin, does not form any caudal fin line (Wada et al., 2008). Similar roles could be played by ter1-3 in tuna, since ter 1 ends up associated to the dorsal part of the caudal fin, whereas the migration of ter3 accompanies the expansion of hypural plate $\mathrm{H} 1$, corresponding to the ventral half of the developing caudal fin. However, whereas in Danioter2-3 are deposited by the primordium, in Thunnus and Sarda ter2 is formed post-embryonically, and quickly generates ter3 to complete the terminal pattern. Thus similar larval patterns are achieved by different mechanisms in Danio and in Thunnus/Sarda. It seems conceivable that the highly reproducible sequence of formation of ter1, ter2 and ter3 in tuna embryos ensures that precursor neuromasts T1 and T3 will unerringly form the dorsal and ventral branches of the caudal fin lines. In zebrafish, the ventral branch is occasionally missing, probably due to imprecision in the mechanism of ter neuromast deposition (Wada et al., 2008).

\section{Materials and Methods}

\section{Egg collection}

The bluefin tuna broodstocks were composed of 35 fish with an estimated mean body weight of $100 \mathrm{~kg}$. They had been kept in captivity for 3 years in a floating cage, at El Gorguel (Cartagena, Spain). Fifteen fish were induced to spawn using delivery systems loaded with $\mathrm{GnRHa}$ (Mylonas etal.,£2007) on June 26 and 27, and an egg collector was placed around the cage. Beginning 48-72h later, massive spawning occurred. 2.3 million eggs were collected at dawn on July 30 , with sea water temperature at $23.5^{\circ} \mathrm{C}$. Collected eggs were transported in a 500 l plastic tank supplied with pure oxygen to the IEO facilities at Puerto de Mazarrón, and washed with sterilized sea water. Egg diameter was $1032.13 \pm 32.89 \mu$. Each egg had $1.28 \pm 0.52$ oil globules and its dry weight was $61.82 \pm 1.05 \mu \mathrm{g}$. The exact age of the embryos is not known, as the time of spawning was not precisely determined, but they must have been around 28$34 \mathrm{hpf}$ (hours post-fertilization), assuming they were laid between midnight and 6AM. The onset of primordium migration 


\section{A. Ghysen et al.}

must therefore be close to $24 \mathrm{hpf}$, as in zebrafish.

Atlantic bonito eggs were obtained from captive breeders stocked in IEO land based facility at Puerto de Mazarron, Spain (11 fish with a weight between 2 and $3 \mathrm{~kg}$ ). Natural spawning started on May 13 and extended over more than fifty days. Fish spawned at dusk, between 19 and $22 \mathrm{~h}$. Eggs were collected in the early morning and were washed with sterilized water, cleaned and counted. Fertilization rate was $62 \%$, egg diameter was $1280.88 \pm 35.33 \mu \mathrm{m}$, and each egg had $4.47 \pm 1.41$ oil globules. Temperature was $22^{\circ} \mathrm{C}$.

Cleaned eggs were reared in the IEO facilities at Puerto de Mazarron, or transported by car to IFREMER facilities in Palavas, France, and by air to HCMR facilities in Heraklion, Crete. Rearing conditions ranged from the semi-extensive mesocosm (at HCMR) to the pseudo green water (at IEO and HCMR) and clear water methods (at IFREMER and IEO), with no detectable difference in the PLL pattern. Surface skimmers were installed between 2-4 and 10 days post-hatch (dph) to maintain a clean surface and facilitate swim bladder inflation. Temperature, salinity and dissolved oxygen were monitored daily in the tank. Phytoplankton was added twice daily in the tanks with mesocosm and pseudo-green conditions, in order to maintain a green medium until $14 \mathrm{dph}$. Feeding was based on enriched rotifers, beginning at $2 \mathrm{dph}$, followed by enriched $2 \mathrm{~d}$ instar Artemianauplii at $9 \mathrm{dph}$, and by newly hatched larvae at $15 \mathrm{dph}$. Weaning to minced fish was initiated at $23 \mathrm{dph}$ in pseudo-green and $35 \mathrm{dph}$ in mesocosm conditions.

\section{Neuromast and nerve labeling}

For live fluorescent labeling of the hair cells, larvae were transfered as gently as possible to a solution of DiAsp (4-(4-diethylaminostyryl)-Nmethylpryridinium iodide (Sigma D-3418), $5 \mu \mathrm{M}$ in sea water, and left in the solution for 15-20 min (or more, to achieve afferent neurite labeling). The larvae were anesthetized in $0.5 \mathrm{mM}$ tricaine (3-aminobenzoic acid ethyl ester) in sea water, and examined under epifluorescence.

For anti-acetylated tubulin immunolabeling, larvae were fixed in $2 \%$ TCA (trichloracetic acid) in sea water, rinsed in phosphate-buffered saline (PBS), and with PBS with $0.7 \%$ triton X-100 (PBT), 10min each. They were then treated for 2 min on ice with pre-chilled $0.25 \%$ trypsin. After two rinses with pre-chilled phosphate buffer, the larvae were post-fixed for $5 \mathrm{~min}$ with $4 \%$ paraformaldehyde. They were rinsed with PBT, preincubated in PBS with $1 \%$ bovin serumalbumin and $10 \%$ lamb serum, incubated overnight at $4^{\circ}$ in anti-acetylated tubulin from Sigma, diluted 1:1000, rinsed for $1 \mathrm{~h}$ in PBT, incubated 8-10 $\mathrm{h}$ in HRP-coupled secondary antibody diluted 1:1000, and processed for HRP reaction.

Fluorescent phalloidin labeling of hair cell microvilli was done as described in Lopez-Schier and Hudspeth, 2006. Dil labeling of the PLL nerve was done by iontophoretic application as described in Fame et al., 2006.

\section{Acknowledgments}

We thank H. Wada for fertile exchanges and for communicating results prior to publication, D. Mylonas for discussions and support, C. DamblyChaudière for comments on the manuscript, and M. Caggiaro and $A$. Corriero for providing preliminary material for this report. This work was carried out with financial support from the Commission of the European Communities, specific RTD programme of Framework Programme 7 , SELFDOTT, "From capture based to self-sustained aquaculture and domestication of bluefin tuna, Thunnus thynnus" (GA 212797) coordinated by F. de la Gandara. It does not necessarily reflect the Commission's views and in no way anticipates its future policy in this area.

\section{References}

COOMBS, S. and MONTGOMERY, J.C. (1999). The enigmatic lateral line system. in: Comparative hearing: fish and amphibians. R.R. Fay and A.N. Popper eds, Springer Verlag, New York, pp. 319-362.
DIJKGRAAF, S. (1963). The functioning and significance of the lateral-line organs. Biol. Rev. 38: 51-105.

FAME, R.M., BRAJON, C. and GHYSEN, A. (2006). Second-order projection from the posterior lateral line in the early zebrafish brain. Neural Dev 1: 4.

FAUCHERRE, A., PUJOL-MARTI, J., KAWAKAMI, K. and LOPEZ-SCHIER, H. (2009). Afferent neurons of the zebrafish lateral line are strict selectors of haircell orientation. PLoS One 4: e4477.

GHYSEN, A. and DAMBLY-CHAUDIERE, C. (2007). The lateral line microcosmos. Genes Dev. 21: 2118-2130

GILMOUR, D., KNAUT, H., MAISCHEIN, H.M. and NUSSLEIN-VOLHARD, C. (2004). Towing of sensory axons by their migrating target cells in vivo. Nat. Neurosci. 7: 491-492.

GOMPEL, N., CUBEDO, N., THISSE, C., THISSE, B., DAMBLY-CHAUDIÈRE, C. and GHYSEN, A. (2001). Pattern formation in the lateral line of zebrafish. Mech Dev. 105: 69-77.

GRANT, K.A., RAIBLE, D.W. and PIOTROWSKI, T. (2005). Regulation of latent sensory hair cell precursors by glia in the zebrafish lateral line. Neuron 45: 6980.

KAWAMURA, G., MASUMA, S., TEZUKA, N., KOISO, M., JINBO, T. and NAMBA, K. (2003). Morphogenesis of sense organs in the bluefin tuna Thunnus orientalis. In The Big Fish Bang. (Eds. H.I. Browman and A.B. Skiftesvik). Institute of Marine Research, Bergen, pp. 123-135.

LOPEZ-SCHIER, H. and HUDSPETH, A.J. (2005). Supernumerary neuromasts in the posterior lateral line of zebrafish lacking peripheral glia. Proc. Natl. Acad. SCi. USA 102: 1496-1501.

LOPEZ-SCHIER, H. and HUDSPETH, A.J. (2006). A two-step mechanism underlies the planar polarization of regenerating sensory hair cells. Proc. Natl. Acad. SCi. USA 103: 18615-18620.

METCALFE, W.K., KIMMEL, C.B. and SCHABTACH, E. (1985). Anatomy of the posterior lateral line system in young larvae of the zebrafish. J. Comp. Neurol. 233: $377-389$

METCALFE, W.K. (1985). Sensory neuron growth cones comigrate with posterior lateral line primordium cells in zebrafish. J. Comp. Neurol. 238: 218-224.

MYLONAS, C.C, BRIDGES, C., GORDIN, H., BELMONTE, A., GARCIA, A., DE LA GANDARA, F., FAUVEL, C., SUQUET, M., MEDINA, A., PAPADAKI, M., HEINISCH, G., DE METRIO, G., CORRIERO, A., VASSALLO-AGIUS, R., GUZMAN, J.M., MANANOS, E. and ZOHAR, Y. (2007). Preparation and administration of Gonadotropin-Releasing Hormone agonist ( $\mathrm{GnRHa}$ ) implants for the artificial control of reproductive maturation in captive-reared atlantic bluefin tuna (Thunnus thynnus thynnus). Rev Fish Sci15: 183-210.

NAGIEL, A., ANDOR-ARDO, D. and HUDSPETH, A.J. (2008). Specificity of afferent synapses onto plane-polarized hair cells in the posterior lateral line of the larval zebrafish. J. Neurosci. 28: 8442-8453.

PARTRIDGE, B.L., JOHANNSON, J. and KALISH, J. (1983). The structure of schools of giant bluefin tuna in Cape Cod Bay. Environ. Biol. Fishes 9: 253-262.

PICHON, F., GHYSEN, A. (2004). Evolution of posterior lateral line development in fish and amphibians. Evol. Dev. 3: 187-193.

SAPEDE, D., GOMPEL, N., DAMBLY-CHAUDIERE, C., GHYSEN, A. (2002). Cell migration in the postembryonic development of the fish lateral line. Development 129: 605-615.

STEVENS, E. D. AND NEILL, W. H. (1978). Body temperature relations of tunas, especially skipjack. In Fish Physiology, vol. VII (ed. W. S. Hoar and D. J. Randall), pp. 315-359. New York: Academic Press.

VAN TRUMP, W.J. and McHENRY, M.J. (2008). The morphology and mechanical sensitivity of lateral line receptors in zebrafish larvae (Danio rerio). J. Exp. Biol. 211: 2105-2115.

WADA, H, HAMAGUSHI, S., and SAKAIZUMI, M. (2008) Development of diverse lateral line patterns on the teleost caudal fin. Dev. Dyn. 237: 2889-2902.

WADA, H., GHYSEN, A., SATOU, C., HIGASHIJIMA, S., KAWAKAMI, K., HAMAGUCHI, S. and SAKAIZUMI, M. (2010). Dermal morphogenesis controls lateral line patterning during postembryonic development of teleost fish. Dev. Biol. 340: 583-594.

WEBB, J.F. (1989). Gross morphology and evolution of the mechanoreceptive lateral-line systm in teleots fishes. Brain Behav. Evol. 33: 205-222. 


\section{Further Related Reading, published previously in the Int. J. Dev. Biol.}

How animals get their skin patterns: fish pigment pattern as a live Turing wave Shigeru Kondo, Motoko Iwashita and Motoomi Yamaguchi Int. J. Dev. Biol. (2009) 53: 851-856

Zebrafish development and regeneration: new tools for biomedical research

Sebastiaan A. Brittijn, Suzanne J. Duivesteijn, Mounia Belmamoune, Laura F.M.Bertens, Wilbert Bitter, Joost D. de Bruijn, Danielle L. Champagne, Edwin Cuppen, Gert Flik, Christina M. Vandenbroucke-Grauls, Richard A.J. Janssen, Ilse M.L. de Jong, Edo Ronald de Kloet, Alexander Kros, Annemarie H. Meijer, Juriaan R. Metz, Astrid M. van der Sar, Marcel J.M. Schaaf, Stefan Schulte-Merker, Herman P. Spaink, Paul P. Tak, Fons J. Verbeek, Margriet J. Vervoordeldonk, Freek J. Vonk, Frans Witte, Huipin Yuan and Michael K. Richardson Int. J. Dev. Biol. (2009) 53: 835-850

Axial patterning in the developing vertebrate inner ear Tanya T. Whitfield and Katherine L. Hammond Int. J. Dev. Biol. (2007) 51: 507-520

Shaping the mammalian auditory sensory organ by the planar cell polarity pathway Michael Kelly and Ping Chen

Int. J. Dev. Biol. (2007) 51: 535-547

Development of the hair bundle and mechanotransduction

Gowri D. Nayak, Helen S.K. Ratnayaka, Richard J. Goodyear and Guy P. Richardson Int. J. Dev. Biol. (2007) 51: 597-608

Molecular evolution of the vertebrate mechanosensory cell and ear Bernd Fritzsch, Kirk W. Beisel, Sarah Pauley and Garrett Soukup

Int. J. Dev. Biol. (2007) 51: 663-678

Cubozoan jellyfish: an Evo/Devo model for eyes and other sensory systems Joram Piatigorsky and Zbynek Kozmik Int. J Dev Biol. (2004) 48: 719-729
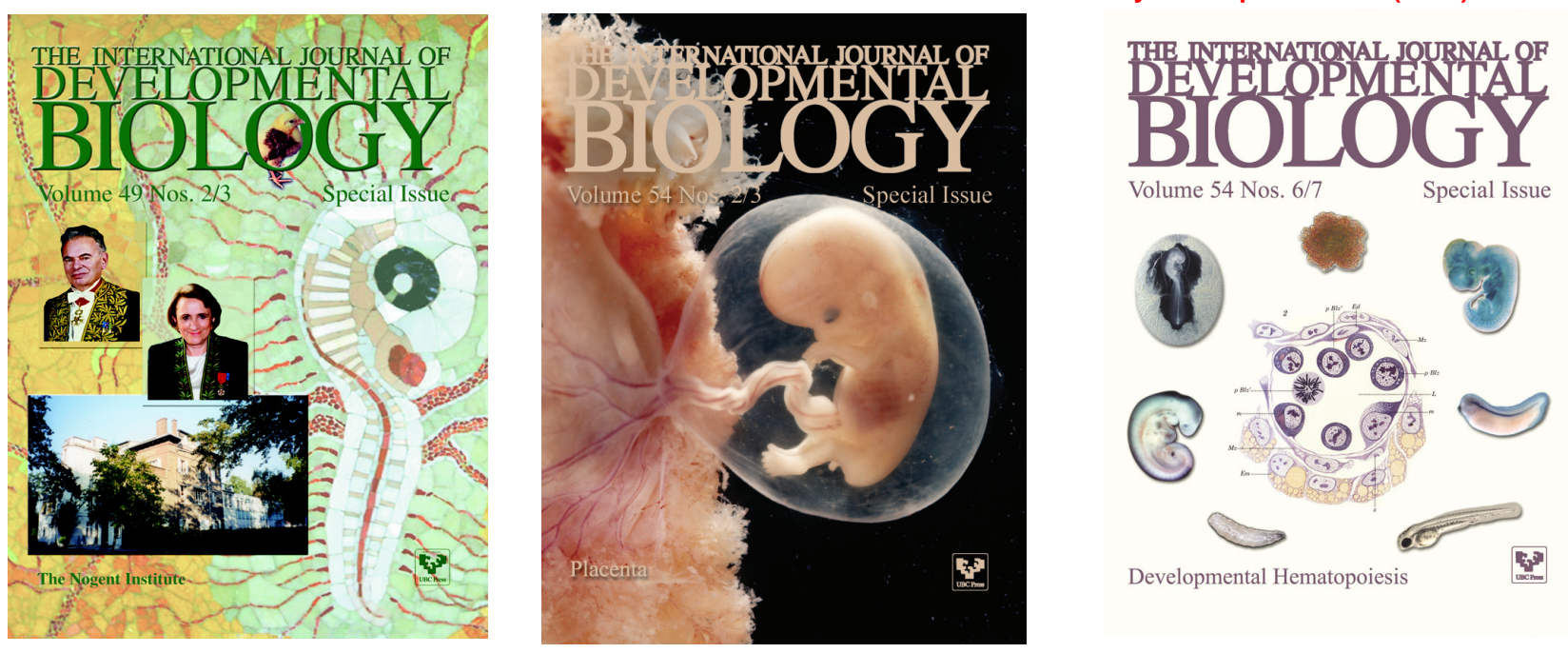